\title{
IMPACT OF IRRIGATION CESSATION ON WETLAND COMMUNITIES WITHIN THE ELK RANCH IN Grand Teton National Park, Moose, Wyoming
}

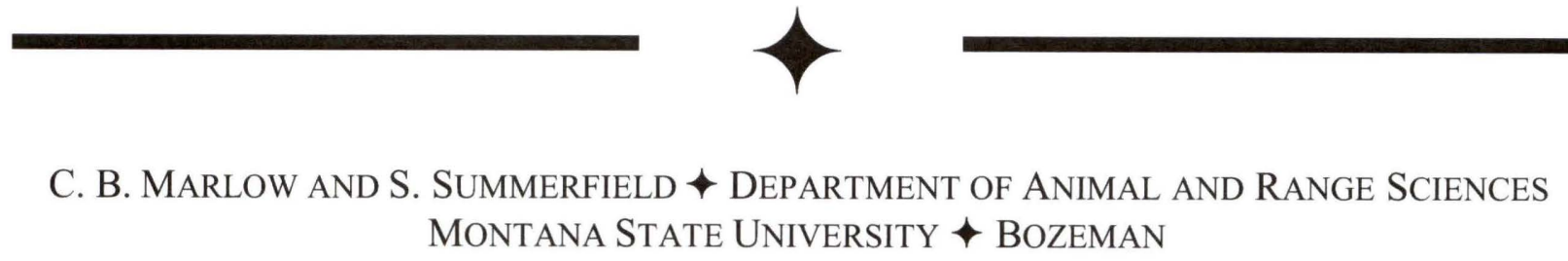

\section{$\downarrow \quad$ INTRODUCTION}

This study began in 2006 to provide an ecologically based decision platform for Grand Teton National Park (GTNP) managers to use when evaluating the pros and cons of continuing the historic Elk Ranch irrigation operation. Ideally, this platform would also provide criteria for identifying landscapes within the irrigated hay meadows that would experience the most rapid change in vegetation community structure if the decision were to terminate irrigation operations. These criteria would aid in the identification of areas where species composition could quickly change as growing conditions shifted to the drier conditions common in surrounding undeveloped range and forestland. Once identified these sites could be closely managed to prevent invasive non-native species from disrupting site re-occupation by native upland species. To accomplish this goal the study was designed to 1) identify soil and hydrologic features associated with wetland and upland plant communities in the hayfield complex and 2) monitor shallow groundwater patterns associated with these wetland complexes. Predictive responses generated from the soil/vegetation inventories would then be compared with the recorded groundwater patterns to validate the measures as indicators of vegetation community change. If successful, these criteria will also be useful for identifying the potential for wetland mitigation and rehabilitation at other localities within Grand Teton National Park.

\section{$\downarrow \quad$ STUdy OBJECTIVES}

The primary objectives of this research have been to characterize plant communities, soils, and shallow groundwater in flood irrigated hay meadows in the Elk Ranch, test for relationships between vegetation composition, soil characteristics and ground water elevation and determine if those relationships can be used to differentiate between natural and irrigation created wetlands. Most of the vegetation and soils inventory was completed in 2007 (Marlow and Summerford 2008). A statistical analysis of field records and laboratory results was conducted in the spring of 2009 as part of a Masters thesis (Summerford 2009). Shallow groundwater monitoring initiated in July 2007 continued through spring 2009 to acquire a more detailed understanding of the relationship between irrigation and the formation of wetland soil and vegetation characteristics at the Elk Ranch.

\section{$\uparrow \quad$ Methods}

\section{Field Work:}

A sample adequacy test of the 2006/2007 soils and vegetation data indicated that several of the sampling areas (Fig. 1) had been under sampled. Based on this outcome seven new plots were inventoried during July 2008. A shallow groundwater monitoring well $(1.5 \mathrm{~m}$ deep) was hand augered into place at each plot location following collection of the requisite soil and vegetation information (Fig. 1). The new soil and vegetation data was added to the earlier data and statistical summarization began in October 2008. While the initial study design had anticipated the use of ANOV 
and regression tests to identify differences between the identified blocks or sampling areas it quickly became apparent that individual plant species cover varied so greatly from one plot to the next in the same block that a different statistical test was necessary. Consequently, a non-parametric test was used to evaluate the soils and vegetation data. This was done with the $\mathrm{R}$ statistical program (R Development Core Team 2008). Depth to soil saturation, depth to groundwater, depth to redox features, redox abundance, redox contrast, organic matter content, percent vegetation cover by species, and WIV were compared across all plots without attention to blocks. Vegetation data were analyzed as a weighted factor composed of percent foliar cover and the species' wetland indicator value (percent cover * WIV, e.g. 30 percent cover with an 83 WIV equals 24.9). The Bray and Curtis ordination (BC) and nonmetric multidimensional scaling (NMDS) tests were used to identify dissimilarity (D2) of vegetation and soil characteristics among all sample plots (Kent and Coker 1992, Quinn and Keough 2002, R Development Core Team 2008). Points with $\mathrm{D}^{2}=0.0$ would be identical to each other while points with $\mathrm{D}^{2}=1.0$ would be completely dissimilar (Kent and Coker 1992).

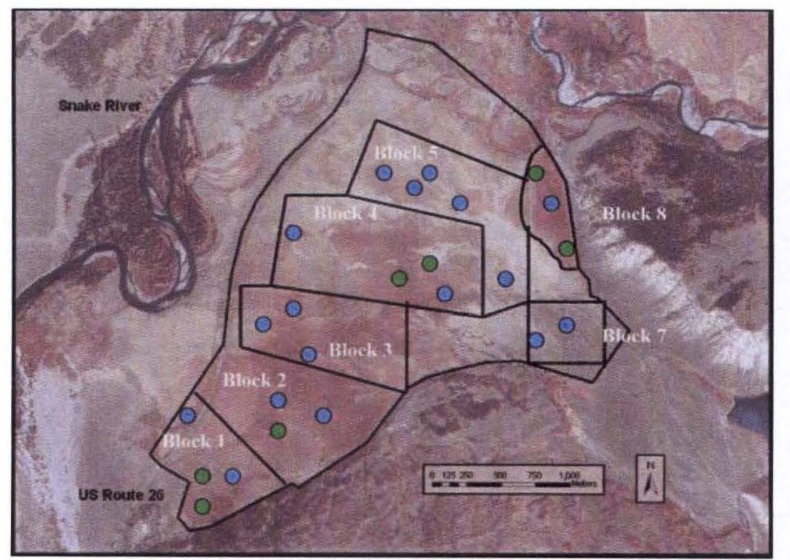

Fig. 1. Location of sampling blocks within the Elk Ranch hay meadows used for characterizing wetland community composition, soil characteristics and depth to groundwater. Block boundaries follow apparent drainage ways. Blue dots represent vegetation plots and associated groundwater monitoring wells established in 2007 while green dots indicate the additional sampling and well installation carried out in 2008 .

Groundwater records were summarized graphically using depth to groundwater in individual wells for the months July through October in 2007 and May through October 2008. Summary monthly patterns where then compared to the predicted responses developed from the soil/vegetation analysis. Plots that exhibited increases in groundwater during irrigation followed by substantial declines without any overwinter recovery were considered non-wetland sites.

\section{RESULTS AND DISCUSSION}

Twenty-six of the twenty-eight sample plots met the three criteria for wetland classification listed by the Wetland Training Institute (2001). Even though sample plots $\mathrm{B} 7 \mathrm{P} 2$ and $\mathrm{B} 7 \mathrm{P} 3$ did not meet the hydrophytic vegetation parameter, they were still included in statistical comparisons. Wetland Indicator Value (WIV) and soil redox contrast were found to differ most among plots (Table 1). The WIV had a $\mathrm{D}^{2}$ of 0.90 and soil redox contrast a $\mathrm{D}^{2}$ of 0.71 . When wetland indicator status for vegetation at sample points was plotted against soil redox contrast values for the same point a definite pattern emerged (Fig. 2). Plots with high levels of groundwater for extended periods (B1P1, B1P4 and B6P2) had few redox soil features. This relationship fits established wetland soil characteristics; profiles that experience high groundwater levels over the year have few redoximorphic features because of anaerobic conditions. At the opposite end of the spectrum were study plots like B7P1 and B7P2 that also exhibited no soil redox features because the profiles were never saturated long enough to mobilize iron oxides. An initial prediction of plot (landscape point) response to cessation of irrigation was developed from the dissimilarity patterns (Table 2 ). While there are strong differences between those plots that are clearly natural wetlands and those sites that were originally upland, about seven plots exhibited characteristics common to both wetlands and uplands (Fig. 3). Review of overwinter (recovery) groundwater patterns for ' $07 /$ ' 08 and '08/'09 indicated that the wetland plant community at these "transitional" plots was likely due to augmentation of deeper water tables by irrigation. The records illustrate the influence of irrigation on groundwater levels at the transitional plots for wells B8P1, B8P2 and B8P3 (Fig. 4a). Groundwater increases lagged behind the annual closure of irrigation (22-28 June) by about 30 days and then declined to depths as much as $1.5 \mathrm{~m}$ to $1.8 \mathrm{~m}$ by October of the same year. In the apparent natural wetlands (B1P1, B1P2, $\mathrm{B} 1 \mathrm{P} 3$ and $\mathrm{B} 1 \mathrm{P} 4)$, there was no mid-summer peak in groundwater elevation and water levels were static or had increased by October (Fig. 4b). Inclusion of groundwater patterns with the WIV and soil redox information removed some of the uncertainty from the predicted responses for areas of the hayfield. Based on groundwater patterns most of the plots listed as uncertain response in Table 2 would transition to upland vegetation should park service managers decide to suspend irrigation on the Elk Ranch hayfields (Table 3). When all of the plots are located on a map the original blocking did represent general differences 
within the hayfields. It is quite likely that the area represented by Block 1 will continue as a wetland after irrigation is suspended (Figs. 1 and 5). The remaining areas within the hayfield will probably transition to upland vegetation community types at different rates and with different species trajectories once irrigation is suspended. For example, the area surrounding plots B2P2, B2P4 and B3P2 may shift very slowly to upland species because
2008 and May 2009 suggests the possibility of a subsurface recharge pathway that would support wetland species until drought or grazing pressure shifted competitive advantage to upland species.

\begin{tabular}{lc}
\hline Measured characteristic & Dissimilarity $\left(\mathrm{D}^{2}\right)$ of plots \\
\hline Wetland index value & 0.90 \\
Redox contrast & 0.71 \\
Depth to groundwater & 0.49 \\
Redox abundance & 0.47 \\
Organic matter & 0.40 \\
Depth to saturation & 0.37 \\
Foliar cover & 0.23 \\
\hline
\end{tabular}

Table 1. Measured vegetation and soil characteristics and the associated dissimilarity values $\left(\mathrm{D}^{2}\right)$ for plots at the Elk Ranch, Moran, WY. Note: $\mathrm{D}^{2}$ values approachingn 0 indicate a high degree of similarity in that attribute between all plots.

minor groundwater recovery noted between October

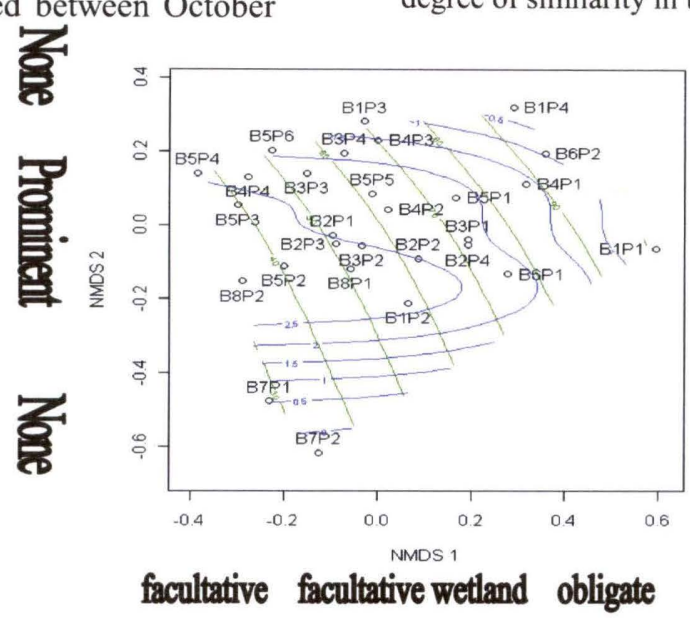

Fig. 2. Nonmetric, multidimensional scaling of weighted wetland vegetation index values (straight lines) and weighted average soil redox contrast values (contour lines) for all sample plots at the Elk Ranch, Grand Teton National Park, Moran, WY

\begin{tabular}{|c|c|c|c|}
\hline $\begin{array}{l}\text { Sample } \\
\text { plot }\end{array}$ & $\begin{array}{l}\text { Soil redox } \\
\text { contrast }^{1}\end{array}$ & $\begin{array}{l}\text { Weighted average } \\
\text { WIV }^{2}\end{array}$ & $\begin{array}{l}\text { Predicted c.t. } \\
\text { response }^{3}\end{array}$ \\
\hline $\mathrm{B} 7 \mathrm{P} 1$ & None & 31.22 & Remain as upland \\
\hline $\mathrm{B} 7 \mathrm{P} 2$ & None & 32.33 & Remain as upland \\
\hline $\mathrm{B} 1 \mathrm{P} 4$ & None & 92.66 & Remain as wetland \\
\hline $\mathrm{B} 1 \mathrm{P} 1$ & None & 100.00 & Remain as wetland \\
\hline $\mathrm{B} 1 \mathrm{P} 3$ & Faint & 74.85 & Remain as wetland \\
\hline $\mathrm{B} 2 \mathrm{P} 4$ & Faint & 83.07 & Remain as wetland \\
\hline $\mathrm{B} 5 \mathrm{P} 3$ & Distinct & 42.15 & Transition to upland \\
\hline $\mathrm{B} 3 \mathrm{P} 2$ & Distinct & 52.61 & Response uncertain \\
\hline $\mathrm{B} 2 \mathrm{P} 2$ & Distinct & 62.55 & Response uncertain \\
\hline B5P5 & Distinct & 62.75 & Response uncertain \\
\hline $\mathrm{B} 5 \mathrm{P} 1$ & Distinct & 66.32 & Response uncertain \\
\hline B5P6 & Distinct & 66.85 & Response uncertain \\
\hline B4P3 & Distinct & 75.80 & Remain as wetland \\
\hline $\mathrm{B} 8 \mathrm{P} 2$ & Prominent & 29.50 & Transition to upland \\
\hline B2P3 & Prominent & 39.49 & Transition to upland \\
\hline B5P2 & Prominent & 40.16 & Transition to upland \\
\hline B8P1 & Prominent & 49.12 & Transition to upland \\
\hline $\mathrm{B} 4 \mathrm{P} 2$ & Prominent & 62.64 & Response uncertain \\
\hline $\mathrm{B} 1 \mathrm{P} 2$ & Prominent & 63.25 & Response uncertain \\
\hline B4P1 & Prominent & 78.41 & Remain as wetland \\
\hline B3P1 & Prominent & 84.91 & Remain as wetland \\
\hline
\end{tabular}

${ }^{1}$ Soil data were from the upper $40 \mathrm{~cm}$ of the soil profile ${ }^{3}$ community type (c.t.)

${ }^{2}$ Wetland index value (WIV)

Table 2. Predicted community type transition following suspension of flood irrigation in the Elk Ranch hayfields, GTNP Moran, WY. 


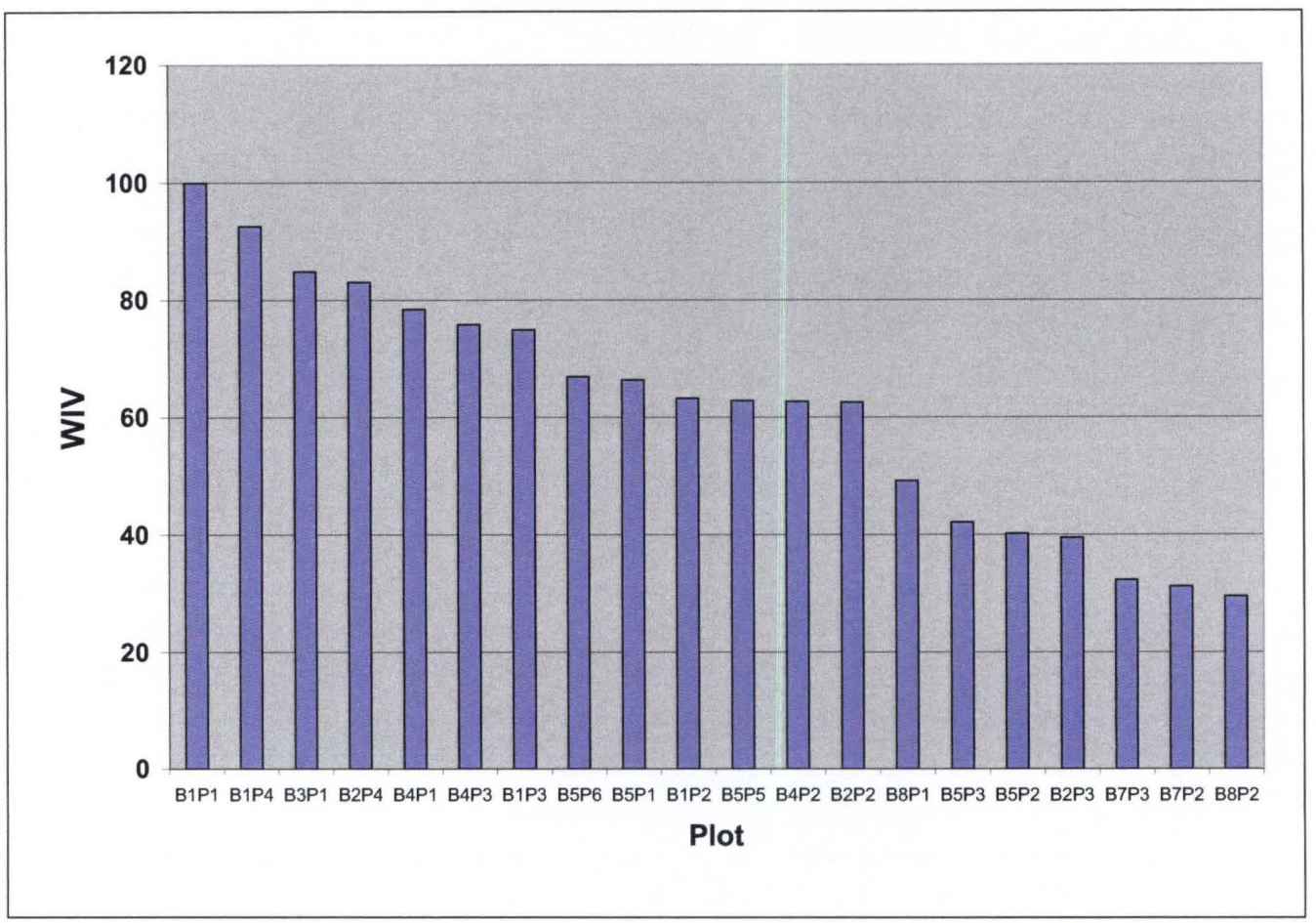

Fig. 3. Calculated wetland indicator values (\% foliar cover $\mathrm{x}$ wetland index) for sampled soil/vegetation plots in the Elk Ranch hayfields, Grand Teton National Park, Moran, WY.

\begin{tabular}{|c|c|c|c|}
\hline $\begin{array}{l}\text { Sample } \\
\text { plot }\end{array}$ & $\begin{array}{l}\text { Soil redox } \\
\text { contrast }^{1}\end{array}$ & Weighted average & $\begin{array}{l}\text { Predicted c.t. } \\
\text { response }^{3}\end{array}$ \\
\hline B7P1 & None & 31.22 & Remain as upland \\
\hline B7P2 & None & 32.33 & Remain as upland \\
\hline B1P4 & None & 92.66 & Remain as wetland \\
\hline B1P1 & None & 100.00 & Remain as wetland \\
\hline B1P3 & Faint & 74.85 & Remain as wetland \\
\hline $\mathrm{B} 2 \mathrm{P} 4$ & Faint & 83.07 & Remain as wetland \\
\hline B5P3 & Distinct & 42.15 & Transition to upland \\
\hline B3P2 & Distinct & 52.61 & Transition to upland \\
\hline B2P2 & Distinct & 62.55 & Transition to upland \\
\hline B5P5 & Distinct & 62.75 & Transition to upland \\
\hline B5P1 & Distinct & 66.32 & Transition to upland \\
\hline B5P6 & Distinct & 66.85 & Transition to upland \\
\hline B4P3 & Distinct & 75.80 & Remain as wetland \\
\hline B8P2 & Prominent & 29.50 & Transition to upland \\
\hline B2P3 & Prominent & 39.49 & Transition to upland \\
\hline B5P2 & Prominent & 40.16 & Transition to upland \\
\hline B8P1 & Prominent & 49.12 & Transition to upland \\
\hline B4P2 & Prominent & 62.64 & Transition to upland \\
\hline B1P2 & Prominent & 63.25 & Remain as wetland \\
\hline B4P1 & Prominent & 78.41 & Remain as wetland \\
\hline $\mathrm{B} 3 \mathrm{P} 1$ & Prominent & 84.91 & Remain as wetland \\
\hline
\end{tabular}

${ }^{1}$ Soil data were from the upper $40 \mathrm{~cm}$ of the soil profile

${ }^{2}$ Wetland index value (WIV)

${ }^{3}$ community type (c.t.)

Table 3. Revised prediction of community type transition following suspension of flood irrigation of the Elk Ranch hayfields, Grand Teton National Park, Moran, WY. 
Block 8 - 2008

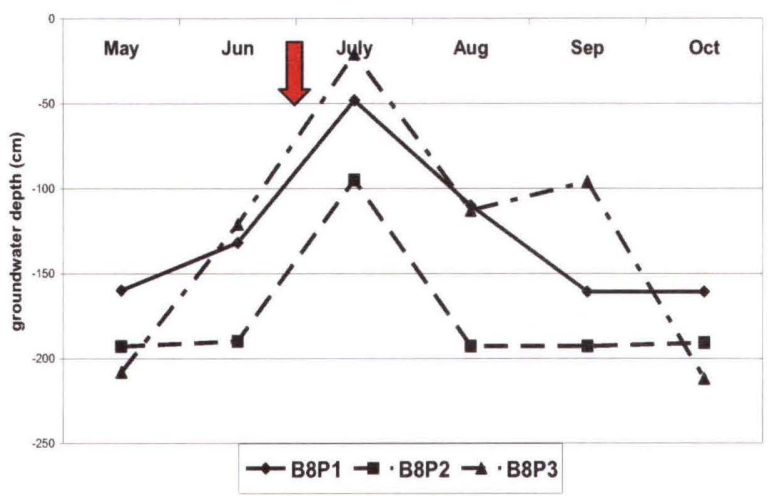

$4 \mathrm{~A}$
Block 1 - 2008

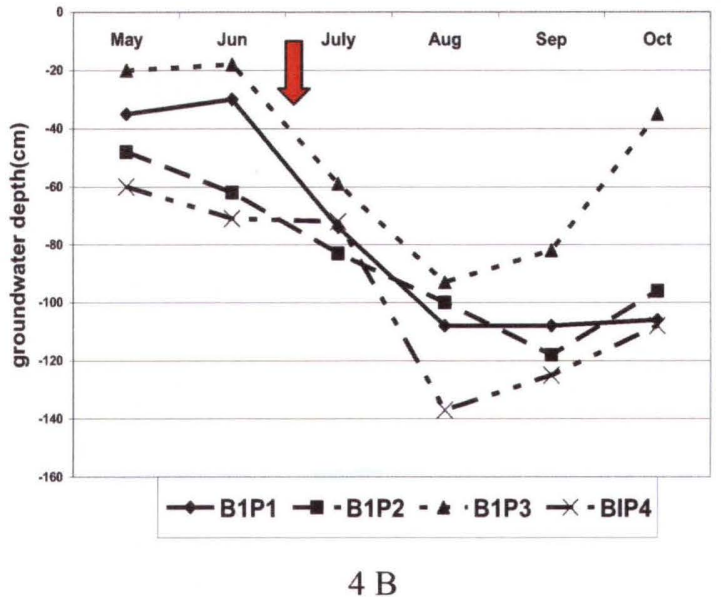

Fig. 4. Groundwater patterns recorded at representative sampling plots in the Elk Ranch hayfield during 2008. Represents when irrigation waters were turned off.

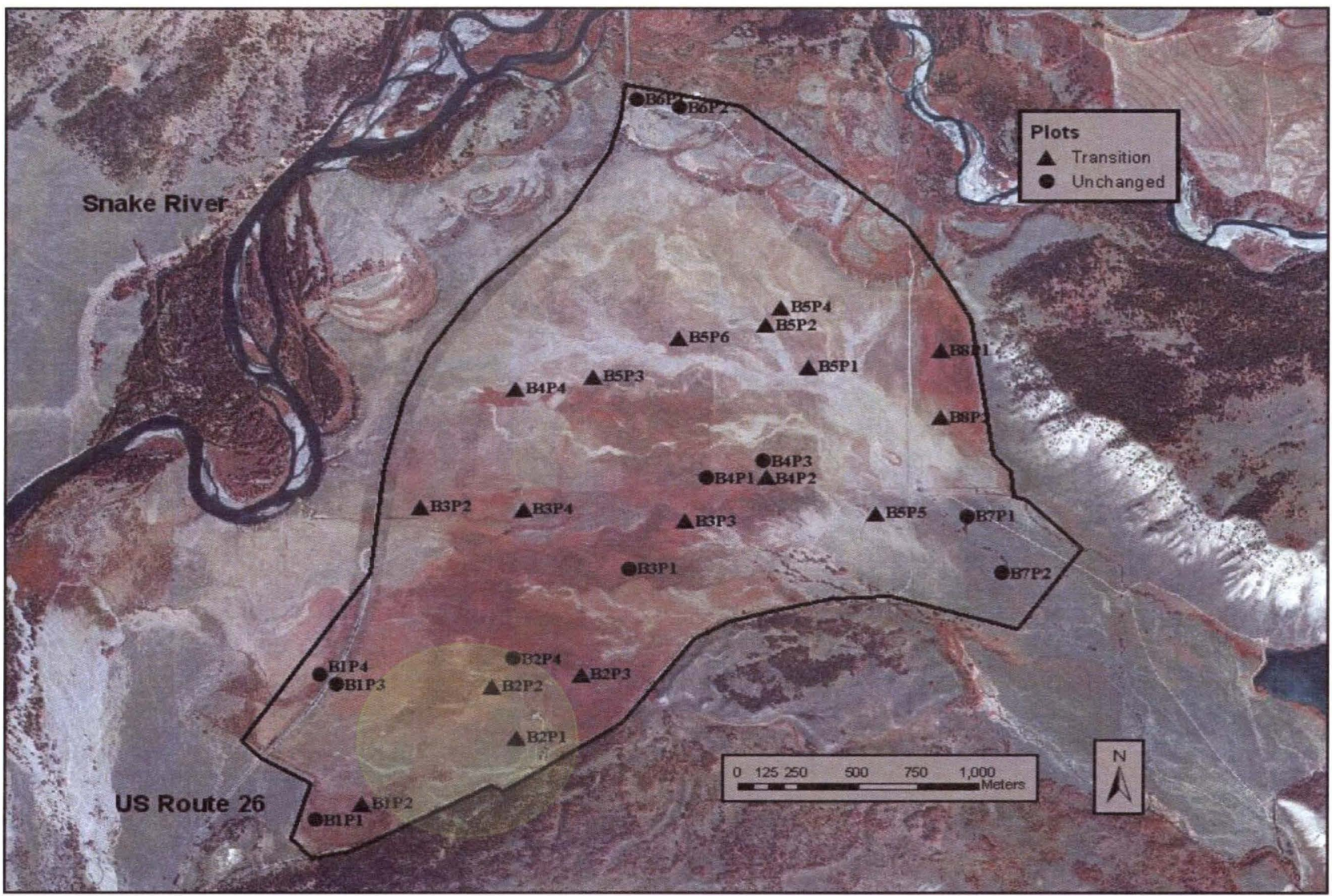

Fig. 5. The shaded area indicates groundwater patterns that will continue to support wetland communities following suspension of irrigation activities. 


\section{ONGOING AND ANTICIPATED EFFORTS}

Groundwater monitoring with continue through October 2009 to verify the interpretations based on the 20062008 outcomes. Confirmation of the groundwater relationship with the observed soil redox and wetland indicator values will strengthen the predictive responses described in this report. While the accuracy of these assessments can only be determined by monitoring these plots for a number of years following a decision to stop irrigating the hayfields, the method could be evaluated through assessment of other hayfield complexes within the park. For example, identification of some wetland indicator species coupled with soil redox features through the inventory of historic channels in other park hayfields would support the utility of this assessment approach. Successful testing of the assessment method off the Elk Ranch would elevate confidence in the decision platform developed from the results generated from this study. Grand Teton National Park Service personnel would then have a powerful tool for the evaluation of areas for wetland rehabilitation or mitigation.

\section{LITERATURE CITED}

Kent, M. and P. Coker. 1992. Vegetation description and analysis: A practical approach. CRC Press, Boca Raton.

Marlow, C.B. and S. Summerford. 2008. Impact of Irrigation Cessation on Wetland Communities within the Elk Ranch, Grand Teton National Park, Moose, Wyoming. Annual Progress Report, University of Wyoming/National Park Service Research Station, University of Wyoming, Laramie, WY.

Quinn, G. and M. Keough. 2002. Experimental design and data analysis for biologists. University Press, Cambridge.

R Development Core Team. 2008. R: A language and environment for statistical computing. $\mathrm{R}$ Foundation for Statistical Computing. Vienna.

Summerford, S. 2009. Characterization of Soil/vegetation on Flood Irrigated Hayfields in Grand Teton National Park, Wyoming: A Predicative Evaluation Tool for Agricultural Wetlands. Masters Thesis, Animal and Range Sciences Department, Montana State University.

Wetland Training Institute, Inc. 2001. Field guide for wetland delineation: 1987 Corps of Engineers manual. Glenwood, NM. 